\title{
Web-Based Health Information Seeking Among African American and Hispanic Men Living With Chronic Conditions: Cross-sectional Survey Study
}

Ledric D Sherman ${ }^{1}, \mathrm{MA}, \mathrm{PhD}$; Kirby Goidel ${ }^{2}$, MA, PhD; Caroline D Bergeron ${ }^{3}$, MSc, CHES, DrPH; Matthew Lee Smith $^{4}$, MPH, CHES, PhD

\footnotetext{
${ }^{1}$ Department of Health \& Kinesiology, Texas A\&M University, College Station, TX, United States

${ }^{2}$ Public Policy Research Institute \& Department of Political Science, Texas A\&M University, College Station, TX, United States

${ }^{3}$ Public Health Agency of Canada, Ottawa, ON, Canada

${ }^{4}$ Department of Environmental and Occupational Health, Center for Population Health and Aging, Texas A\&M University, College Station, TX, United States
}

\section{Corresponding Author:}

Ledric D Sherman, MA, PhD

Department of Health \& Kinesiology

Texas A\&M University

4243 TAMU

College Station, TX, 77843

United States

Phone: 19798451266

Email: 1sherman@tamu.edu

\section{Abstract}

Background: Previous research has identified disparities in seeking and using web-based health information to inform health-related behaviors. Relatively few studies however have examined the correlations between web-based health information seeking and use based on race, gender, age, and the presence of chronic health conditions.

Objective: In this study, we identify factors associated with seeking and using web-based health information among a uniquely vulnerable and intersectional population—middle-aged and older (40 years and older) African American and Hispanic men living with one or more chronic conditions.

Methods: Survey responses were collected from a purposive sample of African American and Hispanic men using Qualtrics web-based survey management software. To qualify for inclusion in the study, respondents had to identify as African American or Hispanic men, report having at least one chronic condition, and be aged 40 years and older. A series of binary logistic regression models was created using backward elimination. Statistical significance was determined at $P<.05$ for all analyses.

Results: Web-based health information seeking among African American and Hispanic men is a function of education, the presence of multiple chronic conditions, frustration with health care providers, internet use, and the perceived reliability of web-based health information. The use of web-based health information to inform interactions with health care providers was more common among African American and Hispanic men, who rated their health as relatively good, perceived barriers to care, used technology regularly, and took more daily medications.

Conclusions: Understanding the factors that influence African American and Hispanic men seeking web-based health information may help improve the care and treatment of chronic conditions. African American and Hispanic men seek web-based health information as a substitute for routine care and to inform their discussions with health care providers.

(J Med Internet Res 2021;23(7):e26180) doi: 10.2196/26180

\section{KEYWORDS}

minority men; online information seeking; chronic disease; communication with health care providers; mobile phone 


\section{Introduction}

\section{Background}

Information seeking encompasses the act of accumulating information to gain clarity or affirm knowledge about a specific topic [1]. Well-informed patients maintain a sense of control over their illness and are better able to cope with uncertainties related to outcomes and treatments [2-5]. Correspondingly, knowledgeable patients engage with medical providers in planning their care, managing their treatments, and adapting more readily to therapeutic schedules [6,7]. Insufficient health information, in contrast, can have unfavorable health consequences $[2,8]$.

Health-related information can be obtained from supportive social networks, health care providers, and the media, including the internet, television, radio, books, or magazines $[9,10]$. Web-based health resources provide an optimal way to disseminate health information because there is the "immediacy of information access, the accessibility at any time of the day or night, the potential continual updating of information and the wider range of information available" [11]. However, disparities exist in terms of who pursues or seeks web-based health information and how the information is used to inform subsequent interactions with health care providers $[7,12,13]$. Although men use the internet more often than women, they use it less frequently to seek health information [14]. Men are also less likely to seek routine medical care than women and therefore have fewer opportunities to discuss web-based health information with their health care providers [15]. Race and ethnicity are also associated with internet-based health information seeking $[16,17]$. Historically, health information seeking was less common among racial and ethnic minorities because of limited internet access and lower health literacy skills $[12,13,18-20]$. However, recent research has suggested that these differences may be dwindling, with African Americans relying more heavily on web-based health information for health care [21,22]

Other factors associated with web-based information include education [19], self-reported health status [23,24], time spent with medical providers and frustrations in communicating with these providers [25,26], internet use [23,27], and the perceived reliability of web-based health information [28]. Previous research does not provide enough clarity on how these factors might affect internet-based information-seeking behaviors of African American and Hispanic men with chronic conditions; however, there is reason to expect some differences. Some studies have examined web-based health information seeking by race $[29,30]$ or by sex, specifically for men with chronic diseases [31], but did not focus specifically on African American and Hispanic men with chronic conditions. This population has been found to experience important barriers to disease self-management [32], have less access to health insurance and preventative care [33], have higher rates of preventable hospitalizations [34], and are more likely to die from their chronic conditions compared with non-Hispanic White men [35]. Seeking and using credible web-based health information may represent an important health-promoting activity.
In this paper, we seek to understand web-based health information seeking among African American and Hispanic men. Our motivation is both substantive and methodological. First, African American and Hispanic men are less likely to seek preventative care and treatment, which subsequently affects health outcomes. Understanding the factors that lead to seeking web-based health information may lead to better health outcomes. Second, African American and Hispanic men are hard-to-reach populations in survey research, meaning that they are often underrepresented in probability-based samples.

\section{Objective}

In this 2-phase study, we contribute to the existing literature by investigating web-based health information seeking and use among African American and Hispanic men aged 40 years and older with one or more chronic conditions. In phase 1, we identify factors associated with seeking web-based health information in the past year about (1) a specific disease or medical problem and (2) medical treatments and procedures. Then, in phase 2, we identify factors associated with discussing web-based health information with primary medical professionals only among those men who sought health information on the internet and had a routine physician visit within the past year.

\section{Methods}

\section{Overview}

Due to increased costs and declining response rates, scholars increasingly rely on web-based panels when studying hard-to-reach or intersectional populations [36]. African American and Hispanic men with chronic conditions and aged 40 years or older, for example, are relatively small segments of the overall population, making random selection via probability sampling costly and inefficient. Due to distrust of medical providers, African American and Hispanic men are often less responsive to requests to participate in health-related research [37].

With this in mind, the sample in this study was designed using Qualtrics (Systems, Applications, and Products in Data Processing Societas Europaea) web-based panels to identify African American and Hispanic men aged 40 years and older with at least one chronic health condition. We used the Checklist for Reporting Results of Internet E-Surveys for web-based surveys in our description of data collection [38]. Qualtrics web-based panels are opt-in research panels ideal for studies targeting hard-to-reach populations. Qualtrics panels provide access to previously identified research participants with known characteristics, and panel participants are recruited and compensated for their participation by Qualtrics. Potential participants were directed to the programmed survey where they were provided with a description of the study and information relating to informed consent. The tradeoff for cost effectiveness using Qualtrics is that the sample might not be representative of the target population.

The survey questionnaire was constructed by the authors who identified validated questions from previous research related to web-based health information seeking and other health-related 
behaviors. An initial draft of the survey was carefully reviewed by experts in the field who were not a part of the research team and made suggestions for inclusion (or exclusion) of specific items. The final data were carefully reviewed by the research team, eliminating questionable responses (eg, respondents who completed the survey too quickly). In addition, filter questions for age, race, and the presence of one or more chronic conditions were used to further qualify potential respondents and ensure that only qualified respondents completed the survey questionnaire. The survey instrument included a wide range of health-related attitudes and behaviors. Overall, data were collected from 2028 men who met the inclusion criteria. This study was approved by the Institutional Review Board (\#2018-1684) of Texas A\&M University.

Inspired by Pettus et al [39], who examined internet use and web-based health information seeking among older women in a 2-phase study, we modeled this study to focus on web-based health information seeking among middle-aged and older men. To be included in phase 1 of our analytic sample, men also had to report using the internet within the past 2 weeks. Men who did not meet this criterion were excluded from phase 1 analyses. The 2 dependent variables in phase 1 assessed web-based health information seeking and use, which was measured using 2 items.
First, participants were asked if they had looked for information on the internet about "a specific disease or medical problem." Response choices for this item were "yes" and "no." Second, participants were asked if they had looked for information on the internet about "a certain medical treatment or procedure." Response choices for this item were "yes" and "no."

Building upon findings in phase 1, to be included in phase 2 of our analytic sample, men must have reported "yes" to looking for information on the internet about "a specific disease or medical problem" or "a certain medical treatment or procedure. In addition, to avoid confounding the results with issues of health care access, these minority men must have reported having a routine physician visit in the past year to be included in phase 2. Men who did not meet this criterion were excluded from phase 2 analyses. The dependent variable in phase 2 assessed whether men shared findings from their web-based health information seeking with medical professionals. More specifically, participants were asked if they spoke with a medical professional about what they found on the web. Response choices for this item were "yes" and "no." Figure 1 illustrates the participant flow across both study phases based on the inclusion criteria.

Figure 1. Study flow by analysis phases.

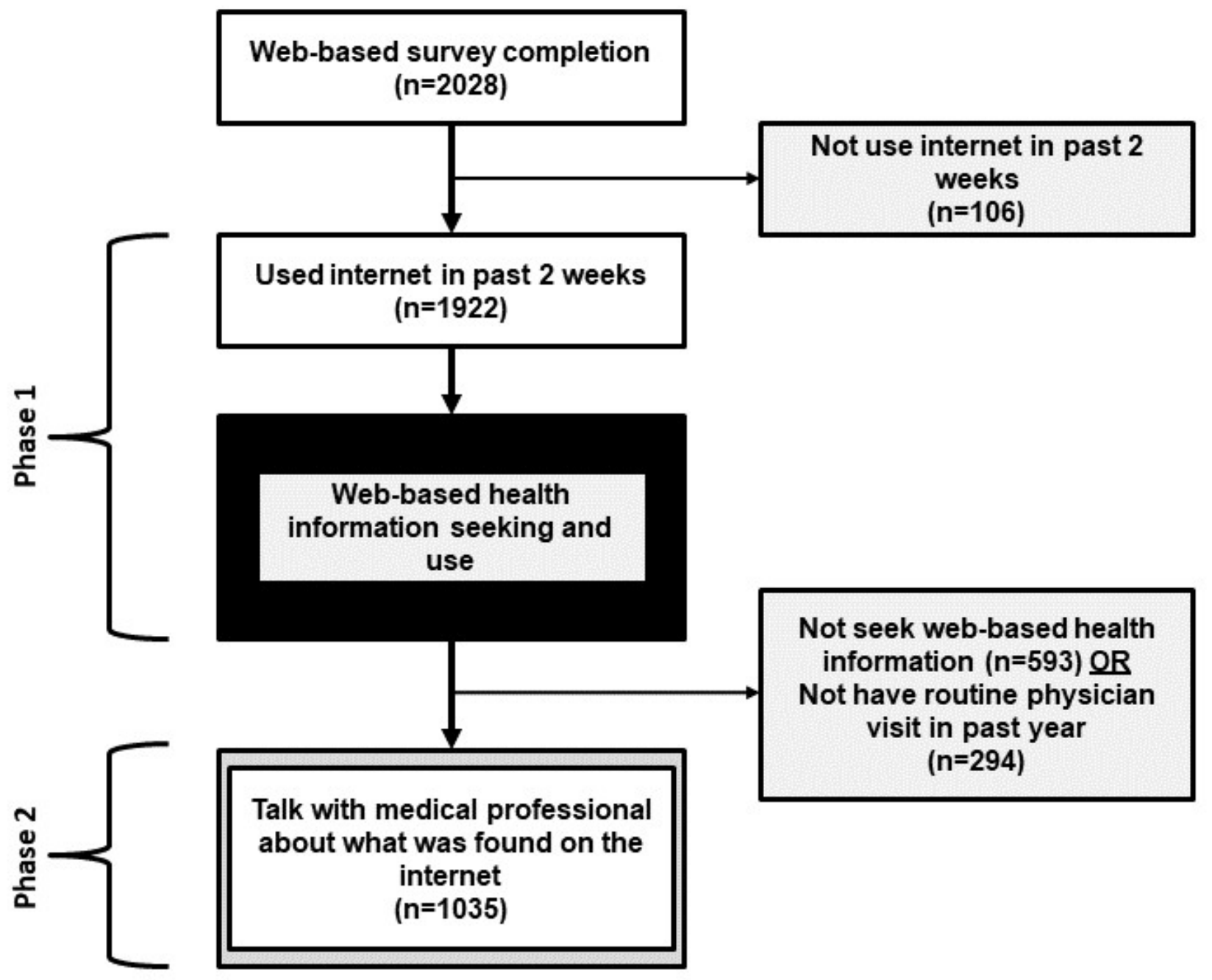


We modeled web-based health information seeking as a function of demographics (age, race, education, marital status, and number of household members), health-related behaviors and status (number of chronic conditions, number of daily medications, having a routine physician visit in the past year, and self-reported health status), available resources for managing care (receiving help to manage care, ability to self-manage diseases, perceived barriers to care, health care frustrations, and participation in programs to prevent or manage chronic illness), and technology use and credibility (use of technology and reliability of web-based health information). We provide brief descriptions of each of these below.

\section{Demographics}

Age was measured in years, with all respondents reporting that they were aged 40 years or older. Race is a dichotomous variable indicating whether the respondent is African American (coded as 0 and serving as the baseline category) or Hispanic (coded as 1). Marital status was measured as a set of dummy variables indicating whether the respondent was single or never married, married or partnered, divorced or separated, or widowed. The number of household members was the total number of people (including the respondent) currently living in the household. The demographic variables in our models were primarily included as controls.

\section{Health-Related Behaviors}

This set of variables included health conditions, regular doctor visits, and self-reported health status. Overall, it is expected that individuals with worse health, meaning more chronic conditions and poor self-reported health status, would be more likely to look for health information on the internet. The number of chronic conditions was calculated using a "check all that apply" list of the following 19 chronic health conditions: (1) asthma, emphysema, chronic breathing problem, or lung problem; (2) arthritis or rheumatic disease; (3) cancer or cancer survivor; (4) chronic pain; (5) depression or anxiety; (6) diabetes; (7) heart disease; (8) high cholesterol; (9) hypertension; (10) kidney disease; (11) memory problem; (12) obesity; (13) osteoporosis; (14) obstructive sleep apnea; (15) schizophrenia or other psychotic disorder; (16) stroke; (17) thyroid problem; (18) urinary incontinence; and (19) another chronic condition not listed. In addition, participants were asked to report the number of different medications taken daily (range 0 to $>6$ ), whether they had visited a doctor in the past year (coded 1 if the respondent said yes; 0 otherwise), and a 5-point Likert scale measure of their self-reported health status ranging from poor (coded as 1) to excellent (coded as 0 ).

\section{Resources for Managing Care}

In addition to health-related behaviors and concerns, individuals with more resources available for managing care should be more likely to seek health information on the internet. This begins with perceptions of whether or not they are receiving the support they need to improve their health and manage their care, measured using a 5-point scale ranging from never (1) to always (5) $[23,24]$. Due to the skewed nature of the responses, these were collapsed into the never, rarely, or occasionally versus frequently or always range.
The disease self-management efficacy scale was included to gauge individual respondents' sense of control over the management of their health care [25,26], Respondents were asked about their level of agreement (using a 4-point Likert scale) with the following statements: (1) when all is said and done, I am the person who is responsible for taking care of my health; (2) taking an active role in my own health care is the most important thing that affects my health; (3) I know what each of my prescribed medications do; (4) I am confident that I can tell whether I need to go see the doctor or whether I can take care of a health problem myself; (5) I am confident I can tell a doctor concerns I have even if he or she does not ask; (6) I am confident I can follow through on medical treatments I may need to do at home; (7) I have been able to maintain (keep up with) lifestyle changes such as eating right or exercising; (8) I know how to prevent problems with my health; (9) I am confident I can figure out solutions when new problems arise with my health; and (10) I am confident that I can maintain lifestyle changes like eating right and exercising, even during times of stress. Scores for this scale ranged from 4 to 40 , with higher scores indicating higher efficacy.

The use of web-based health information may also reflect barriers to care, reflecting the need for help and support in managing care and treatment. The barriers to self-care scale were measured based on levels of agreement with the following statements: (1) I need help learning what I should be doing to take better care of my health; (2) I need help learning how to take better care of my health in a way that works for me and my life; (3) I do not have the money it takes to do things that will improve my health or condition; (4) I wish I could change and do things that are healthier, but I just do not think I can; and (5) all of my different health problems and conditions make it difficult for me to take better care of myself. Scale values ranged from 5 to 20, with higher scores indicating more barriers.

Patients also seek web-based health information when their experiences with medical providers are frustrating. The health care frustration scale assesses whether participants felt any of the following frustrations [23,24]: (1) felt tired of describing their same conditions and problems every time they went to a hospital or doctor's office, (2) left the hospital or doctor's office and felt confused about what they should do, (3) wished their doctor had more time to spend talking with them, (4) felt tired of feeling on their own when it came to taking care of their health problems, (5) felt that their doctor did not realize what it was really like for them at home trying to take care of their health problems, and (6) wished they had a friend or family member who could go to the doctor with them. Responses were coded as "never" (1), "occasionally" (2), or "frequently" (3). Scores for this scale ranged from 6 to 18 , with higher scores indicating higher health care frustrations [34].

Finally, respondents might gain knowledge about their chronic condition and insight into their medical condition by participating in a program specifically designed to prevent or treat chronic illnesses [40-43]. For example, the Chronic Disease Self-Management Program (CDSMP) is a universal program that applies to any chronic condition, although disease-specific translations also exist to build skills to manage arthritis, diabetes, chronic pain, and HIV and AIDS [44]. Previous research has 
indicated that CDSMP improved outcomes while reducing costs [45].

\section{Technology Use and Credibility}

Aside from health concerns and conditions, web-based health information seeking is also a function of the level of comfort in using technology and perceptions regarding the credibility of information found alone. Technology use was measured by whether the respondent had used the following technologies in the past 2 weeks: computer (laptop, desktop, or tablet), smartphone, email (from a computer, smart phone, or tablet), internet (from a computer, smart phone, or tablet), Skype or other video systems (from a computer, smart phone, or tablet), or Facebook or other social media (eg, Twitter). Responses were coded from 0-6 depending on how many of these technologies individual participants reported having used in the past 2 weeks. Perceptions regarding the credibility of web-based information are measured with the question of how reliable they believe information on the internet is about health or medical conditions. Responses were coded from 0 (not at all) to 3 (extremely).

\section{Data Analysis}

All analyses were performed using SPSS version 25 (IBM Corporation). We calculated descriptive statistics for all variables of interest, which were compared across the 2 dependent variables in phase 1. Chi-square tests were used for categorical variables and two-tailed independent sample $t$ tests were used for continuous and count variables, after assessing frequency distributions and tests for variance equality. As each dependent variable was dichotomous, we used logistic regression to estimate the models. Model selection was based on stepwise regression using backward elimination of nonsignificant predictor variables. Predictor variables were eliminated when they did not improve the overall model fit, as reflected by the likelihood ratio test. The final regression models included the fewest predictors from the model that provided the best fit to the data. Omnibus tests of model coefficients confirmed no significant loss of variance during backward entry steps for any of the 3 models fitted in this study. However, both full and final reduced regression models are presented in the tables described in the Results section. For all analyses, statistical significance was set at $P<.05$.

\section{Results}

\section{Phase 1 Study Results}

Table 1 provides the sample characteristics for the two phase 1 dependent variables. Among the 1922 men who had used the internet in the past week, 57.34\% (1102) reported seeking information about a specific disease or medical problem and $50.83 \%$ (977) reported seeking information about a medical treatment or procedure. About 58.32\% (1121/1922) of the participants were African American and 41.68\% (801/1922) were Hispanic. The average age of the sample was 56.63 (SD $10.01)$ years. The majority of participants attended at least some college $(1536 / 1922,79.92 \%)$, over half were married or partnered (997/1922, 51.87\%), and most reported having a routine physician visit in the past year $(1627 / 1922,84.65 \%)$. On average, participants reported living with 2.58 (SD 1.61) other people, having 3.93 (SD 2.9) chronic conditions, and taking 3.39 (SD 2.02) medications daily. About 57.7\% $(1109 / 1922)$ reported that they frequently or always received the help and support needed to improve their health and manage their health problems, and $17.43 \%$ (335/1922) reported attending a program to prevent or manage their chronic illness in the past year. 
Table 1. Sample characteristics by web-based information-seeking behavior $(\mathrm{N}=1922)$.

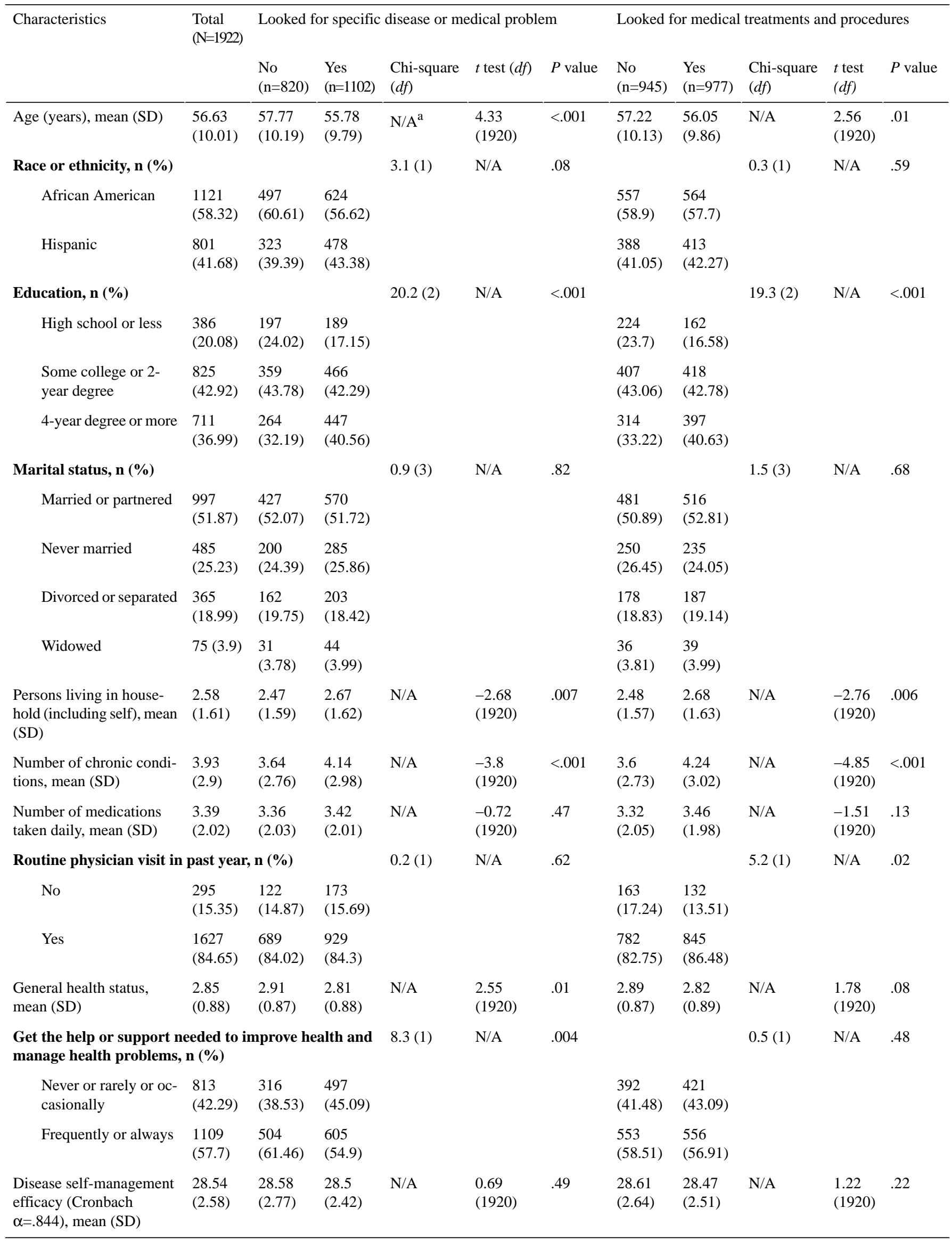




\begin{tabular}{|c|c|c|c|c|c|c|c|c|c|c|c|}
\hline \multirow[t]{2}{*}{ Characteristics } & \multirow{2}{*}{$\begin{array}{l}\text { Total } \\
(\mathrm{N}=1922)\end{array}$} & \multicolumn{5}{|c|}{ Looked for specific disease or medical problem } & \multicolumn{5}{|c|}{ Looked for medical treatments and procedures } \\
\hline & & $\begin{array}{l}\text { No } \\
(n=820)\end{array}$ & $\begin{array}{l}\text { Yes } \\
(\mathrm{n}=1102)\end{array}$ & $\begin{array}{l}\text { Chi-square } \\
(d f)\end{array}$ & $t$ test $(d f)$ & $P$ value & $\begin{array}{l}\text { No } \\
(n=945)\end{array}$ & $\begin{array}{l}\text { Yes } \\
(\mathrm{n}=977)\end{array}$ & $\begin{array}{l}\text { Chi-square } \\
(d f)\end{array}$ & $\begin{array}{l}t \text { test } \\
(d f)\end{array}$ & $P$ value \\
\hline $\begin{array}{l}\text { Barriers to self-care } \\
\text { (Cronbach } \alpha=.844 \text { ), mean } \\
\text { (SD) }\end{array}$ & $\begin{array}{l}11.48 \\
(3.64)\end{array}$ & $\begin{array}{l}10.96 \\
(3.69)\end{array}$ & $\begin{array}{l}11.87 \\
(3.55)\end{array}$ & N/A & $\begin{array}{l}-5.47 \\
(1920)\end{array}$ & $<.001$ & $\begin{array}{l}11.04 \\
(3.62)\end{array}$ & $\begin{array}{l}11.91 \\
(3.61)\end{array}$ & N/A & $\begin{array}{l}-5.26 \\
(1920)\end{array}$ & $<.001$ \\
\hline $\begin{array}{l}\text { Health care frustrations } \\
\text { (Cronbach } \alpha=.856 \text { ), mean } \\
\text { (SD) }\end{array}$ & $\begin{array}{l}9.45 \\
(3.13)\end{array}$ & $\begin{array}{l}8.85 \\
(2.93)\end{array}$ & $\begin{array}{l}9.89 \\
(3.2)\end{array}$ & N/A & $\begin{array}{l}-7.4 \\
(1920)\end{array}$ & $<.001$ & $\begin{array}{l}8.86 \\
(2.9)\end{array}$ & $\begin{array}{l}10.01 \\
(3.24)\end{array}$ & N/A & $\begin{array}{l}-8.2 \\
(1920)\end{array}$ & $<.001$ \\
\hline $\begin{array}{l}\text { Sources of technology use } \\
\text { in past } 2 \text { weeks, mean } \\
\text { (SD) }\end{array}$ & $\begin{array}{l}4.98 \\
(0.8)\end{array}$ & $\begin{array}{l}4.87 \\
(0.81)\end{array}$ & $\begin{array}{l}5.07 \\
(0.78)\end{array}$ & N/A & $\begin{array}{l}-5.64 \\
(1920)\end{array}$ & $<.001$ & $\begin{array}{l}4.85 \\
(0.8)\end{array}$ & $\begin{array}{l}5.12 \\
(0.77)\end{array}$ & N/A & $\begin{array}{l}-7.46 \\
(1920)\end{array}$ & $<.001$ \\
\hline $\begin{array}{l}\text { Perceived reliability of in- } \\
\text { formation received on inter- } \\
\text { net about health or medical } \\
\text { conditions, mean (SD) }\end{array}$ & $\begin{array}{l}1.40 \\
(0.69)\end{array}$ & $\begin{array}{l}1.26 \\
(0.69)\end{array}$ & $\begin{array}{l}1.51 \\
(0.68)\end{array}$ & N/A & $\begin{array}{l}-7.75 \\
(1920)\end{array}$ & $<.001$ & $\begin{array}{l}1.27 \\
(0.68)\end{array}$ & $\begin{array}{l}1.53 \\
(0.68)\end{array}$ & N/A & $\begin{array}{l}-8.4 \\
(1920)\end{array}$ & $<.001$ \\
\hline \multicolumn{4}{|c|}{$\begin{array}{l}\text { Ever attend program to prevent or manage chronic ill- } \\
\text { ness in past year, } n(\%)\end{array}$} & $22.4(1)$ & N/A & $<.001$ & & & $38.7(1)$ & N/A & $<.001$ \\
\hline No & $\begin{array}{l}1587 \\
(82.57)\end{array}$ & $\begin{array}{l}716 \\
(87.31)\end{array}$ & $\begin{array}{l}871 \\
(79.04)\end{array}$ & & & & $\begin{array}{l}832 \\
(88.04)\end{array}$ & $\begin{array}{l}755 \\
(77.27)\end{array}$ & & & \\
\hline Yes & $\begin{array}{l}335 \\
(17.43)\end{array}$ & $\begin{array}{l}104 \\
(12.68)\end{array}$ & $\begin{array}{l}231 \\
(20.26)\end{array}$ & & & & $\begin{array}{l}113 \\
(11.95)\end{array}$ & $\begin{array}{l}222 \\
(22.72)\end{array}$ & & & \\
\hline
\end{tabular}

${ }^{\mathrm{a}}$ N/A: not applicable.

When comparing sample characteristics by the 2 web-based health information-seeking behaviors (ie, both looked on the internet for information about specific diseases or medical problems and medical treatments and procedures), on average, participants who sought health information on the internet were significantly younger, lived with more people in their household, had more chronic conditions, reported more barriers to self-care, and reported higher health care frustrations. A significantly larger proportion of men who sought web-based health information were more educated and attended a program to prevent or manage their chronic illness in the past year. On average, participants who sought health information on the internet reported using more sources of technology and perceived health and medical information received on the internet to be more reliable.

Table 2 presents the results for seeking web-based information for a specific disease or medical condition among those reporting the use of the internet in the past 2 weeks. Compared with men who did not seek web-based health information for a specific disease or medical condition, men who had some college or a 2-year degree (odds ratio [OR] 1.35, 95\% CI 1.04-1.74; $P=.02$ ), had a 4-year degree or higher (OR 1.91, 95\% CI 1.45-2.50; $P<.001)$, and attended a program to prevent or manage their chronic illness (OR 1.40, 95\% CI 1.07-1.83; $P=.01$ ) were more likely to seek web-based information for a specific disease or medical condition. For each unit increase in self-reported chronic conditions (OR 1.04, 95\% CI 1-1.08; $P=.03$ ), health care frustrations (OR 1.09, 95\% CI 1.05-1.12; $P<.001$ ), sources of technology used (OR 1.27, 95\% CI 1.12-1.44; $P<.001$ ), and perceived reliability of health and medical information received on the internet (OR 1.70, 95\% CI 1.46-1.97; $P<.001$ ), the odds of seeking information on the internet for a specific disease or medical condition increased. For each unit increase in self-reported health status, the odds of seeking information on the internet for a specific disease or medical condition decreased (OR 0.86, 95\% CI 0.76-0.97; $P=.01$ ). 
Table 2. Factors associated with looking on the internet for information about a specific disease or medical problem $(\mathrm{N}=1922)^{\mathrm{a}}$.

\begin{tabular}{|c|c|c|c|c|c|c|}
\hline \multirow[t]{2}{*}{ Variable } & \multicolumn{3}{|l|}{ Full model } & \multicolumn{3}{|c|}{ Reduced model } \\
\hline & $\beta(\mathrm{SE})$ & $P$ value & $\mathrm{OR}^{\mathrm{b}}(95 \% \mathrm{CI})$ & $\beta(\mathrm{SE})$ & $P$ value & OR $(95 \% \mathrm{CI})$ \\
\hline Age & $-.01(0.01)$ & .21 & $0.99(0.98-1)$ & $-.01(0.01)$ & .09 & $0.99(0.98-1)$ \\
\hline \multicolumn{7}{|l|}{ Race or ethnicity } \\
\hline African American & $\underline{-}^{\mathrm{c}}$ & - & 1 & - & - & 1 \\
\hline Hispanic & $.16(0.10)$ & .12 & $1.17(0.96-1.43)$ & $.17(0.10)$ & .09 & $1.19(0.98-1.45)$ \\
\hline \multicolumn{7}{|l|}{ Education } \\
\hline High school or less & - & - & 1 & - & - & 1 \\
\hline Some college or 2-year degree & $.29(0.13)$ & .03 & $1.33(1.03-1.72)$ & $.3(0.13)$ & .02 & $1.35(1.04-1.74)$ \\
\hline 4-year degree or more & $.64(0.14)$ & $<.001$ & $1.89(1.43-2.49)$ & $.65(0.14)$ & $<.001$ & $1.91(1.45-2.50)$ \\
\hline Married or partnered & - & - & 1 & N/A ${ }^{d}$ & N/A & N/A \\
\hline Never married & $-.02(0.13)$ & .92 & $0.99(0.76-1.28)$ & N/A & N/A & N/A \\
\hline Divorced or separated & $-.02(0.14)$ & .89 & $0.98(0.75-1.28)$ & $\mathrm{N} / \mathrm{A}$ & N/A & N/A \\
\hline Widowed & $.20(0.26)$ & .44 & $1.22(0.74-2.03)$ & $\mathrm{N} / \mathrm{A}$ & N/A & $\mathrm{N} / \mathrm{A}$ \\
\hline Persons living in household (including self) & $.04(0.03)$ & .25 & $1.04(0.97-1.11)$ & N/A & N/A & N/A \\
\hline Number of chronic conditions & $.04(0.02)$ & .049 & $1.04(1-1.08)$ & $.04(0.02)$ & .03 & $1.04(1-1.08)$ \\
\hline Number of medications taken daily & $.01(0.03)$ & .63 & $1.01(0.96-1.07)$ & N/A & N/A & N/A \\
\hline \multicolumn{7}{|l|}{ Routine physician visit in past year } \\
\hline No & - & - & 1 & $\mathrm{~N} / \mathrm{A}$ & N/A & $\mathrm{N} / \mathrm{A}$ \\
\hline General health status & $-.13(0.07)$ & .046 & $0.88(0.77-1)$ & $-.15(0.06)$ & .01 & $0.86(0.76-0.97)$ \\
\hline \multicolumn{7}{|l|}{ Get the help or support needed } \\
\hline Never or rarely or occasionally & - & - & 1 & $\mathrm{~N} / \mathrm{A}$ & $\mathrm{N} / \mathrm{A}$ & N/A \\
\hline Frequently or always & $-.14(0.11)$ & .22 & $0.87(0.7-1.09)$ & $\mathrm{N} / \mathrm{A}$ & N/A & N/A \\
\hline Disease self-management efficacy & $.01(0.02)$ & .64 & $1.01(0.97-1.05)$ & N/A & N/A & N/A \\
\hline Barriers to self-care & $.01(0.02)$ & .38 & $1.01(0.98-1.05)$ & N/A & N/A & N/A \\
\hline Health care frustrations & $.07(0.02)$ & $<.001$ & $1.07(1.03-1.12)$ & $.08(0.02)$ & $<.001$ & $1.09(1.05-1.12)$ \\
\hline Sources of technology use in past 2 weeks & $.24(0.06)$ & $<.001$ & $1.27(1.12-1.44)$ & $.24(0.06)$ & $<.001$ & $1.27(1.12-1.44)$ \\
\hline Perceived reliability of information received on internet & $.54(0.08)$ & $<.001$ & $1.72(1.48-1.99)$ & $.53(0.08)$ & $<.001$ & $1.7(1.46-1.97)$ \\
\hline
\end{tabular}

\section{Ever attend program to prevent or manage chronic illness in past year}

\begin{tabular}{llllllll} 
No & - & - & 1 & - & - & 1 & \\
Yes & $.31(0.14)$ & .02 & $1.37(1.04-1.79)$ & $.34(0.14)$ & .01 & $1.4(1.07-1.83)$ \\
\hline
\end{tabular}

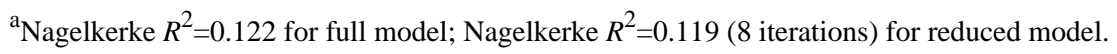

${ }^{\mathrm{b}} \mathrm{OR}$ : odds ratio.

${ }^{\mathrm{C}}$ Not available; referent category for independent variables.

${ }^{\mathrm{d}} \mathrm{N} / \mathrm{A}$ : not applicable; referent category for dependent variable (not looking on the internet for information about a specific disease or medical problem).

Table 3 presents the results for seeking web-based information for medical treatments and procedures among those reporting having used the internet in the past 2 weeks. Compared with men who did not seek web-based information about medical treatments and procedures, men who had a college education or a 2 -year degree (OR 1.32, 95\% CI 1.02-1.72; $P=.03$ ), had a 4-year degree or higher (OR 1.72, 95\% CI 1.31-2.25; $P<.001$ ), attended a routine physician visit in the past year (OR 1.48, 95\% CI 1.13-1.94; $P=.004)$, and attended a program to prevent or manage their chronic illness (OR 1.59, 95\% CI 1.22-2.08; $P=.001$ ) were more likely to seek web-based information about medical treatments and procedures. For each unit increase in 
self-reported chronic conditions (OR 1.06, 95\% CI 1.02-1.1; medical information received on the internet (OR 1.69, 95\% CI $P=.001$ ), health care frustrations (OR 1.12, 95\% CI 1.09-1.16; 1.46-1.95; $P<.001$ ), the odds of seeking web-based information $P=.001$ ), sources of technology used (OR $1.44,95 \%$ CI about medical treatments and procedures increased.

$1.27-1.63 ; P<.001)$, and the perceived reliability of health and

Table 3. Factors associated with seeking on the internet information about medical treatments and procedures $(\mathrm{N}=1922)^{\mathrm{a}, \mathrm{b}}$.

\begin{tabular}{|c|c|c|c|c|c|c|}
\hline \multirow[t]{2}{*}{ Variable } & \multicolumn{3}{|l|}{ Full model } & \multicolumn{3}{|c|}{ Reduced model } \\
\hline & $\beta(\mathrm{SE})$ & $P$ value & $\mathrm{OR}^{\mathrm{c}}(95 \% \mathrm{CI})$ & $\beta(\mathrm{SE})$ & $P$ value & OR $(95 \% \mathrm{CI})$ \\
\hline Age & $0(0.01)$ & .77 & $1(0.99-1.01)$ & $\mathrm{N} / \mathrm{A}^{\mathrm{d}}$ & N/A & N/A \\
\hline \multicolumn{7}{|l|}{ Race or ethnicity } \\
\hline African American & $\mathrm{L}^{\mathrm{e}}$ & - & 1 & N/A & N/A & N/A \\
\hline Hispanic & $.05(0.1)$ & .61 & $1.05(0.86-1.29)$ & N/A & N/A & N/A \\
\hline \multicolumn{7}{|l|}{ Education } \\
\hline High school or less & - & - & 1 & - & - & 1 \\
\hline Some college or 2-year degree & $.28(0.13)$ & .04 & $1.33(1.02-1.72)$ & $.28(0.13)$ & .03 & $1.32(1.02-1.72)$ \\
\hline 4-year degree or more & $.54(0.14)$ & $<.001$ & $1.72(1.3-2.26)$ & $.54(0.14)$ & $<.001$ & $1.72(1.31-2.25)$ \\
\hline \multicolumn{7}{|l|}{ Marital status } \\
\hline Married or partnered & - & - & 1 & N/A & N/A & N/A \\
\hline Never married & $-.21(0.13)$ & .13 & $0.82(0.63-1.06)$ & N/A & N/A & N/A \\
\hline Divorced or separated & $.05(0.14)$ & .70 & $1.05(0.81-1.38)$ & N/A & N/A & N/A \\
\hline Widowed & $.04(0.26)$ & .89 & $1.04(0.63-1.72)$ & N/A & N/A & N/A \\
\hline Persons living in household (including self) & $.04(0.03)$ & .24 & $1.04(0.97-1.11)$ & N/A & N/A & N/A \\
\hline Number of chronic conditions & $.05(0.02)$ & .006 & $1.05(1.02-1.1)$ & $.06(0.02)$ & .001 & $1.06(1.02-1.1)$ \\
\hline Number of medications taken daily & $0(0.03)$ & .99 & $1(0.95-1.06)$ & N/A & N/A & N/A \\
\hline \multicolumn{7}{|l|}{ Routine physician visit in past year } \\
\hline No & - & - & 1 & - & - & 1 \\
\hline Yes & $.40(0.15)$ & .007 & $1.49(1.11-1.99)$ & $.39(0.14)$ & .004 & $1.48(1.13-1.94)$ \\
\hline General health status & $-.07(0.07)$ & .32 & $0.94(0.83-1.07)$ & N/A & N/A & N/A \\
\hline \multicolumn{7}{|l|}{ Get the help or support needed } \\
\hline Never or rarely or occasionally & - & - & 1 & N/A & N/A & N/A \\
\hline Get the help or support needed: frequently or always & $.04(0.11)$ & .70 & $1.04(0.84-1.3)$ & N/A & N/A & N/A \\
\hline Disease self-management efficacy & $-.01(0.02)$ & .52 & $0.99(0.95-1.03)$ & N/A & N/A & N/A \\
\hline Barriers to self-care & $.02(0.02)$ & .32 & $1.02(0.98-1.05)$ & N/A & N/A & N/A \\
\hline Health care frustrations & $.1(0.02)$ & $<.001$ & $1.11(1.07-1.15)$ & $.12(0.02)$ & $<.001$ & $1.12(1.09-1.16)$ \\
\hline Sources of technology use in past 2 weeks & $.37(0.06)$ & $<.001$ & $1.45(1.28-1.65)$ & $.36(0.06)$ & $<.001$ & $1.44(1.27-1.63)$ \\
\hline Perceived reliability of information received on internet & $.56(0.08)$ & $<.001$ & $1.75(1.51-2.03)$ & $.53(0.07)$ & $<.001$ & $1.69(1.46-1.95)$ \\
\hline
\end{tabular}
about health or medical conditions

Ever attend program to prevent or manage chronic illness in past year

\begin{tabular}{llllllll} 
No & - & - & 1 & - & - & 1 & \\
Yes & $.44(0.14)$ & .001 & $1.56(1.19-2.04)$ & $.47(0.14)$ & .001 & $1.59(1.22-2.08)$ \\
\hline
\end{tabular}

${ }^{\text {a Nagelkerke }} R^{2}=0.155$ for full model; Nagelkerke $R^{2}=0.148$ (10 iterations) for reduced model.

${ }^{\mathrm{b}}$ The same dependent variable and referent category is used for the full and reduced models.

${ }^{\mathrm{c}} \mathrm{OR}$ : odds ratio.

${ }^{\mathrm{d}} \mathrm{N} / \mathrm{A}$ : not applicable.

${ }^{\mathrm{e}}$ Not available; referent category for independent variables. 


\section{Phase 2 Study Results}

Table 4 presents phase 2 results for the 1035 participants who discussed what they found on the internet with their medical providers among those who had a routine physician visit in the past year. Relative to the $71.4 \%$ (739/1035) of men who reported both web-based health information seeking behaviors (ie, disease-specific information and medical treatments or procedures), men who only looked for information about specific diseases on the internet were significantly less likely to discuss what they found with their medical provider (OR $0.52,95 \% \mathrm{CI}$
$0.37-0.74 ; P<.001)$. Relative to men who did not discuss their web-based findings with medical providers, men who were Hispanic (OR 1.41, 95\% CI 1.09-1.83; $P<.001$ ) and attended a program to prevent or manage their chronic illness (OR 2.19, 95\% CI 1.61-2.98; $P<.001)$ were more likely to discuss the web-based findings with their medical provider. For each unit increase in the number of medications taken daily (OR 1.13, 95\% CI 1.05-1.21; $P=.001$ ), barriers to self-care (OR 1.04, 95\% CI 1-1.08; $P=.04)$, and sources of technology used (OR 1.24, $95 \%$ CI 1.05-1.46; $P=.01$ ), the odds of discussing web-based information with medical providers increased. 
Table 4. Factors associated with discussing online information with medical providers $(n=1035)^{a, b}$.

\begin{tabular}{|c|c|c|c|c|c|c|}
\hline \multirow[t]{2}{*}{ Variable } & \multicolumn{3}{|l|}{ Full model } & \multicolumn{3}{|c|}{ Reduced model } \\
\hline & $\beta(\mathrm{SE})$ & $P$ value & $\mathrm{OR}^{\mathrm{c}}(95 \% \mathrm{CI})$ & $\beta(\mathrm{SE})$ & $P$ value & OR $(95 \% \mathrm{CI})$ \\
\hline \multicolumn{7}{|l|}{ Looked on the internet for health information } \\
\hline Both & ${ }_{-}^{\mathrm{d}}$ & - & 1 & - & - & 1 \\
\hline Only about medical treatments and procedures & $-.35(0.22)$ & .11 & $0.7(0.45-1.09)$ & $-.37(0.22)$ & .09 & $0.69(0.45-1.06)$ \\
\hline Only about specific diseases of medical problems & $-.6(0.18)$ & .001 & $0.55(0.39-0.79)$ & $-.65(0.18)$ & $<.001$ & $0.52(0.37-0.74)$ \\
\hline Age & $0(0.01)$ & .77 & $1(0.99-1.02)$ & $\mathrm{N} / \mathrm{A}^{\mathrm{e}}$ & N/A & N/A \\
\hline \multicolumn{7}{|l|}{ Race or ethnicity } \\
\hline African American & - & - & 1 & - & - & 1 \\
\hline Hispanic & $.36(0.14)$ & .01 & $1.43(1.09-1.87)$ & $.35(0.13)$ & .01 & $1.41(1.09-1.83)$ \\
\hline \multicolumn{7}{|l|}{ Education } \\
\hline High school or less & - & - & 1 & $\mathrm{~N} / \mathrm{A}$ & N/A & $\mathrm{N} / \mathrm{A}$ \\
\hline Some college or 2-year degree & $.23(0.19)$ & .24 & $1.25(0.86-1.83)$ & N/A & N/A & N/A \\
\hline 4-year degree or more & $.17(0.2)$ & .39 & $1.19(0.8-1.76)$ & N/A & N/A & N/A \\
\hline \multicolumn{7}{|l|}{ Marital status } \\
\hline Married or partnered & - & - & 1 & N/A & N/A & $\mathrm{N} / \mathrm{A}$ \\
\hline Never married & $-.11(0.18)$ & .56 & $0.9(0.63-1.28)$ & N/A & N/A & N/A \\
\hline Divorced or separated & $-.13(0.19)$ & .51 & $0.88(0.61-1.28)$ & N/A & N/A & N/A \\
\hline Widowed & $-.06(0.34)$ & .86 & $0.94(0.49-1.82)$ & N/A & N/A & N/A \\
\hline Persons living in household (including self) & $0(0.05)$ & .99 & $1(0.91-1.1)$ & N/A & N/A & N/A \\
\hline Number of chronic conditions & $.01(0.02)$ & .73 & $1.01(0.96-1.06)$ & N/A & N/A & N/A \\
\hline Number of medications taken daily & $.1190 .04)$ & .003 & $1.12(1.04-1.21)$ & $.12(0.04)$ & .001 & $1.13(1.05-1.21)$ \\
\hline General health status & $.1(0.09)$ & .26 & $1.1(0.93-1.31)$ & $.15(0.08)$ & .07 & $1.16(0.99-1.35)$ \\
\hline \multicolumn{7}{|l|}{ Get the help or support needed } \\
\hline Never or rarely or occasionally & - & - & 1 & N/A & N/A & N/A \\
\hline Frequently or always & $.21(0.15)$ & .16 & $1.23(0.92-1.65)$ & N/A & N/A & N/A \\
\hline Disease self-management efficacy & $.02(0.03)$ & .43 & $1.02(0.97-1.08)$ & N/A & N/A & N/A \\
\hline Barriers to self-care & $.04(0.02)$ & .1 & $1.04(0.99-1.09)$ & $.04(0.02)$ & .04 & $1.04(1-1.08)$ \\
\hline Health care frustrations & $.04(0.03)$ & .11 & $1.04(0.99-1.09)$ & $\mathrm{N} / \mathrm{A}$ & N/A & N/A \\
\hline Sources of technology use in past 2 weeks & $.2(0.09)$ & .02 & $1.22(1.03-1.45)$ & $.22(0.09)$ & .01 & $1.24(1.05-1.46)$ \\
\hline $\begin{array}{l}\text { Perceived reliability of information received on internet } \\
\text { about health or medical conditions }\end{array}$ & $.15(0.1)$ & .15 & $1.16(0.95-1.41)$ & N/A & N/A & N/A \\
\hline \multicolumn{7}{|c|}{ Ever attend program to prevent or manage chronic illness in past year } \\
\hline No & - & - & 1 & - & - & 1 \\
\hline Yes & $.7(0.16)$ & $<.001$ & $2.01(1.46-2.77)$ & $.78(0.16)$ & $<.001$ & $2.19(1.61-2.98)$ \\
\hline
\end{tabular}

${ }^{\mathrm{a}}$ Nagelkerke $R^{2}=0.112$ for full model; Nagelkerke $R^{2}=0.101$ (10 iterations) for reduced model.

${ }^{b}$ The same dependent variable and referent category is used for the full and reduced models.

${ }^{\mathrm{c}} \mathrm{OR}$ : odds ratio.

${ }^{\mathrm{d}}$ Not available; referent category for independent variables.

${ }^{\mathrm{e}} \mathrm{N} / \mathrm{A}$ : not applicable. 


\section{Discussion}

\section{Principal Findings}

This study examined health information seeking among a uniquely vulnerable and intersectional population, African American and Hispanic men aged 40 years and older with one or more chronic conditions. The specific results are worth discussing. First, internet-based health information is an important tool for African American and Hispanic men to use to learn about a specific disease or medical problem as well as medical treatments and procedures and to foster patient-provider conversations about these health-related internet searches, as illustrated by about half of the sample looking for information on the internet. Similar to previous studies, our study suggests that men who are younger [46-48], more highly educated $[47,48]$, use technology more often [49], and believe the internet to be a reliable source [50] report seeking web-based health information in the past year to learn about a specific disease or medical treatment.

Those with more chronic conditions and greater health care frustrations were more likely to use the internet for both purposes (ie, to learn about a specific disease and medical treatments). Previous studies have demonstrated that people living with chronic conditions rely on the internet for help and support and might seek to learn about other people's experiences about a disease through web-based discussions [39]. People living with chronic conditions who experienced health care-related frustrations from unfulfilled needs in a medical encounter have been known to report greater functional limitations and greater self-care barriers to manage their condition or disease [51]. Internet-based health information could be used to help meet those needs.

Men who attended a disease prevention or management program in the past year were more likely to look on the internet to learn about a specific disease or medical problem and to learn about medical treatments and procedures. Considering that these evidence-based programs help increase participants' health behaviors and self-efficacy [52], program participants may feel encouraged to seek additional information to better understand the content of their program and their disease. Both web-based and traditional CDSMPs may also provide links, videos, and other resources to supplement the course materials, thereby encouraging program participants to seek this information on the internet as part of their disease self-management.

Interestingly, compared with men who used the internet only to learn about a specific disease or condition, men who reported both web-based health information-seeking behaviors were more likely to speak to their medical professional about what they found on the internet. It is possible that those who search on the web only to learn about a specific disease no longer feel the need to consult a physician, consequently substituting routine care [53]. Men who seek information on both diseases and treatments may have greater concerns about the credibility of web-based information or about their ability to evaluate this information [53]. Those who searched for treatments and procedures in addition to the general condition may also be exposed to web-based medical advertisements that encourage them to speak to their doctor about these treatment options [53-56]. Through their internet searches, patients reported increased confidence, control, and comfort in discussing their condition and treatments with their medical provider [57]; enhanced understanding of the medical jargon [58]; and satisfaction of feeling better informed [54]. Hispanic men more frequently discussed what they found on the internet with medical professionals. Studies suggest that web-based health information seeking gives Hispanic patients the confidence to discuss their health concerns with their doctors [30]. In the recent study by Camacho-Rivera et al [59] with a large representative sample of Hispanic adults in the United States, the authors found that Hispanics trusted cancer information from their doctors a lot $(1014 / 1512,67.06 \%)$ compared with information from the internet $(309 / 1512,20.44 \%)$. Although there was an important increase in trusting cancer information on the internet from 2014 to 2018, doctors remained the most trusted source of health information for Hispanics [59]. This study supports our findings that Hispanic men were more likely to talk with medical professionals about their web-based health searches.

Men with chronic conditions who had better general health statuses reported communicating with their medical professionals about what they found on the internet. This result contradicts previous studies [55], which suggest that those in poor health are more likely to talk to their medical providers about their web-based health information seeking than those in good health. However, higher medication intake is associated with poorer health (eg, frailty, disability, and fall risk) [60,61]. Poor health status can also lead to greater self-care barriers [62]. Those who take more medications daily also report more barriers to managing their chronic conditions [50]. Medication and self-care barriers were highlighted in our study as factors associated with discussing web-based health information with a medical professional.

It is possible that those with better health status, those who take more medications daily, and those with more self-care barriers may seek medical care more than once a year. It is known that increased physician visits to stay healthy and to get help to manage chronic conditions [63] may provide greater opportunities to discuss web-based health information-seeking behaviors. Increased visits may lead to better patient-physician interactions where bringing internet-based health information would not be seen as a threat but rather as something to be encouraged [64-66].

\section{Limitations}

This study has several limitations. The cross-sectional nature of this study did not allow for the assessment of causal relationships over time. On the basis of the funding mechanism supporting this study, data were only collected from African American and Hispanic men aged 40 years and older with one or more chronic conditions. Although these subgroups often report health-related disparities, additional insights might have been gained, including men of other races and ethnicities (eg, non-Hispanic White, Asian or Pacific Islander, and American Indian or Alaska Native). We hope that future research will expand the scope of this study and provide additional 
comparisons. This study excludes African American and Hispanic males with one or more chronic conditions who do not have access to the internet. This digital divide continues to disproportionately impact the health of minorities and contribute to social inequalities in the United States [67]. In addition, no information was gathered about health literacy, the types of web-based information sources they used, or the credibility of these information sources (eg, government websites). Future research on internet-based health information-seeking behaviors of African American and Hispanic men with chronic conditions should consider assessing the health literacy level of respondents as well as their knowledge of credible health information sources [68]. In addition, in this study, African American and Hispanic subgroups were included in the analyses. Given the potential differences across racial or ethnic subgroups in terms of sociodemographics, behaviors, perceptions, and health care use, future studies may consider performing analyses on these subgroups separately or making direct comparisons between them.

\section{Conclusions}

Overall, this study provides an overview of health information-seeking behaviors among African American and Hispanic men with chronic conditions. Understanding these factors is crucial to influencing internet-based health communication, improving patient-provider communication, and ultimately improving the care and treatment of African American and Hispanic men.

\section{Conflicts of Interest}

None declared.

\section{References}

1. Lambert SD, Loiselle CG. Health information seeking behavior. Qual Health Res 2007 Oct;17(8):1006-1019. [doi: 10.1177/1049732307305199] [Medline: 17928475]

2. Evans SH, Clarke P. Flaws in health communication. Ann Int Commun Asso 2016 May 18;7(1):225-248. [doi: 10.1080/23808985.1983.11678537]

3. Felton BJ, Revenson TA. Coping with chronic illness: a study of illness controllability and the influence of coping strategies on psychological adjustment. J Consult Clin Psychol 1984;52(3):343-353. [doi: 10.1037/0022-006x.52.3.343]

4. Lerman C, Daly M, Walsh WP, Resch N, Seay J, Barsevick A, et al. Communication between patients with breast cancer and health care providers. Determinants and implications. Cancer 1993 Nov 01;72(9):2612-2620. [doi: 10.1002/1097-0142(19931101)72:9<2612::aid-cncr2820720916>3.0.co;2-f] [Medline: 8402483]

5. Viney LL, Westbrook MT. Coping with chronic illness: strategy preferences, changes in preferences and associated emotional reactions. J Chronic Dis 1984 Jan;37(6):489-502. [doi: 10.1016/0021-9681(84)90032-8]

6. Eraker SA, Kirscht JP, Becker MH. Understanding and improving patient compliance. Ann Intern Med 1984 Feb 01;100(2):258-268. [doi: 10.7326/0003-4819-100-2-258] [Medline: 6362512]

7. Tan SS, Goonawardene N. Internet health information seeking and the patient-physician relationship: a systematic review. J Med Internet Res 2017 Jan 19;19(1):e9 [FREE Full text] [doi: 10.2196/jmir.5729] [Medline: 28104579]

8. Denberg TD, Wong S, Beattie A. Women's misconceptions about cancer screening: implications for informed decision-making. Patient Educ Couns 2005 Jun;57(3):280-285. [doi: 10.1016/j.pec.2004.07.015] [Medline: 15893209]

9. Jacobs W, Amuta AO, Jeon KC. Health information seeking in the digital age: an analysis of health information seeking behavior among US adults. Cogent Social Sciences 2017 Mar 13;3(1):1302785. [doi: 10.1080/23311886.2017.1302785]

10. Williams SL, Ames K, Lawson C. Preferences and trust in traditional and non-traditional sources of health information a study of middle to older aged Australian adults. J Healthc Commun 2019 Jul 22;12(2):134-142. [doi: $10.1080 / 17538068.2019 .1642050]$

11. Cotten SR, Gupta SS. Characteristics of online and offline health information seekers and factors that discriminate between them. Soc Sci Med 2004 Nov;59(9):1795-1806. [doi: 10.1016/j.socscimed.2004.02.020] [Medline: 15312915]

12. Ramanadhan S, Viswanath K. Health and the information nonseeker: a profile. Health Commun 2006 Jul;20(2):131-139. [doi: $10.1207 / \mathrm{s} 15327027 \mathrm{hc} 2002$ 4] [Medline: 16965250$]$

13. Tu H, Cohen GR. Striking jump in consumers seeking health care information. Track Rep 2008 Aug(20):1-8. [Medline: 18770913]

14. Hallyburton A, Evarts LA. Gender and online health information seeking: a five survey meta-analysis. J Cons Health Internet 2014 Jun 04;18(2):128-142. [doi: 10.1080/15398285.2014.902268]

15. Pinkhasov R, Wong J, Kashanian J, Lee M, Samadi DB, Pinkhasov MM, et al. Are men shortchanged on health? Perspective on health care utilization and health risk behavior in men and women in the United States. Int J Clin Pract 2010 Mar;64(4):475-487. [doi: 10.1111/j.1742-1241.2009.02290.x] [Medline: 20456194]

16. Rutten LJ, Squiers L, Hesse B. Cancer-related information seeking: hints from the 2003 Health Information National Trends Survey (HINTS). J Health Commun 2006 Feb;11 Suppl 1(sup001):147-156. [doi: 10.1080/10810730600637574] [Medline: $\underline{16641080]}$

17. Wiltshire J, Cronin K, Sarto GE, Brown R. Self-advocacy during the medical encounter: use of health information and racial/ethnic differences. Med Care 2006 Feb;44(2):100-109. [doi: 10.1097/01.mlr.0000196975.52557.b7] [Medline: 16434908] 
18. Tardy RW, Hale CL. Getting "plugged in": a network analysis of health - information seeking among "stay - at - home moms". Commun Monogr 1998 Dec;65(4):336-357. [doi: 10.1080/03637759809376457]

19. Gidwani R, Zulman D. Association between acute medical exacerbations and consuming or producing web-based health information: analysis from Pew survey data. J Med Internet Res 2015 Jun 23;17(6):e145 [FREE Full text] [doi: 10.2196/jmir.3801] [Medline: 26104000]

20. Ackerson LK, Viswanath K. The social context of interpersonal communication and health. J Health Commun 2009 May 20;14 Suppl 1(sup1):5-17. [doi: 10.1080/10810730902806836] [Medline: 19449264]

21. Rooks RN, Kapral CG, Mathis AL. Chronic conditions may be more important than race or ethnicity in relation to health information seeking and use. J Aging Health 2019 Apr 01;31(4):611-630. [doi: 10.1177/0898264317744643] [Medline: 29254425]

22. Rooks RN, Wiltshire JC, Elder K, BeLue R, Gary LC. Health information seeking and use outside of the medical encounter: is it associated with race and ethnicity? Soc Sci Med 2012 Jan;74(2):176-184. [doi: 10.1016/j.socscimed.2011.09.040] [Medline: 22154611]

23. Li J, Theng Y, Foo S. Predictors of online health information seeking behavior: changes between 2002 and 2012 . Health Informatics J 2016 Dec 26;22(4):804-814 [FREE Full text] [doi: 10.1177/1460458215595851] [Medline: 26261218]

24. Lee YJ, Boden-Albala B, Larson E, Wilcox A, Bakken S. Online health information seeking behaviors of Hispanics in New York City: a community-based cross-sectional study. J Med Internet Res 2014 Jul 22;16(7):e176 [REEE Full text] [doi: 10.2196/jmir.3499] [Medline: 25092120]

25. Bell RA, Hu X, Orrange SE, Kravitz RL. Lingering questions and doubts: online information-seeking of support forum members following their medical visits. Patient Educ Couns 2011 Dec;85(3):525-528. [doi: 10.1016/j.pec.2011.01.015] [Medline: 21315538]

26. Tustin N. The role of patient satisfaction in online health information seeking. J Health Commun 2010 Jan 02;15(1):3-17. [doi: 10.1080/10810730903465491] [Medline: 20390974]

27. Lin CA, Atkin DJ, Cappotto C, Davis C, Dean J, Eisenbaum J, et al. Ethnicity, digital divides and uses of the internet for health information. Comput Hum Behav 2015 Oct;51:216-223. [doi: 10.1016/j.chb.2015.04.054]

28. Ye Y. Correlates of consumer trust in online health information: findings from the health information national trends survey. J Health Commun 2011 Jan 30;16(1):34-49. [doi: 10.1080/10810730.2010.529491] [Medline: 21086209]

29. Fareed N, Swoboda CM, Jonnalagadda P, Walker DM, Huerta TR. Differences between races in health information seeking and trust over time: evidence from a cross-sectional, pooled analyses of HINTS data. Am J Health Promot 2021 Jan 26;35(1):84-92. [doi: 10.1177/0890117120934609] [Medline: $\underline{32588638]}$

30. Peña-Purcell N. Hispanics' use of internet health information: an exploratory study. J Med Libr Assoc 2008 Apr;96(2):101-107 [FREE Full text] [doi: 10.3163/1536-5050.96.2.101] [Medline: 18379664]

31. Sherman LD, Patterson MS, Tomar A, Wigfall LT. Use of digital health information for health information seeking among men living with chronic disease: data from the health information national trends survey. Am J Mens Health 2020 Jan 23;14(1):A [FREE Full text] [doi: 10.1177/1557988320901377] [Medline: 31973642]

32. Rustveld L, Pavlik VN, Jibaja-Weiss ML, Kline KN, Gossey T, Volk RJ. Adherence to diabetes self-care behaviors in English- and Spanish-speaking Hispanic men. Patient Prefer Adherence 2009 Nov 03;3:123-130 [FREE Full text] [doi: 10.2147/ppa.s5383] [Medline: 19936154]

33. National Research Council. In: Bulatao RA, Anderson NB, editors. Understanding Racial and Ethnic Differences in Health in Late Life: A Research Agenda. Washington, DC: The National Academies Press; 2004.

34. Laditka JN, Laditka SB. Race, ethnicity and hospitalization for six chronic ambulatory care sensitive conditions in the USA. Ethn Health 2006 Aug;11(3):247-263. [doi: 10.1080/13557850600565640] [Medline: 16774877]

35. Diabetes and African Americans. Department of Health and Human Services Office of Minority Health. 2015. URL: https:/ /minorityhealth.hhs.gov/omh/browse.aspx?lvl=4\&lvlid=18 [accessed 2021-06-03]

36. Brick JM, Williams D. Explaining rising nonresponse rates in cross-sectional surveys. Ann Am Acad Polit Soc Sci 2012 Nov 26;645(1):36-59. [doi: 10.1177/0002716212456834]

37. Green BL, Partridge EE, Fouad MN, Kohler C, Crayton EF, Alexander L. African-American attitudes regarding cancer clinical trials and research studies: results from focus group methodology. Ethn Dis 2000;10(1):76-86. [Medline: 10764133]

38. Eysenbach G. Improving the quality of Web surveys: the Checklist for Reporting Results of Internet E-Surveys (CHERRIES). J Med Internet Res 2004 Dec 29;6(3):e34 [FREE Full text] [doi: 10.2196/jmir.6.3.e34] [Medline: 15471760]

39. Pettus AJ, Mendez-Luck CA, Bergeron CD, Ahn S, Towne SD, Ory MG, et al. Internet-based resources for disease self-care among middle-aged and older women with chronic conditions. J Womens Health (Larchmt) 2017 Mar;26(3):222-233. [doi: 10.1089/jwh.2016.5843] [Medline: 27779440]

40. Lorig K, Holman H, Sobel D, Laurent D, González V, Minor M. Overview of self-management. In: Living a Healthy Life With Chronic Conditions: Self-management of Heart Disease, Arthritis, Diabetes, Asthma, Bronchitis, Emphysema and Others. Boulder, CO, United States: Bull Publishing Company; 2012:1-390.

41. Lorig K, Sobel DS, Ritter PL, Laurent D, Hobbs M. Effect of a self-management program on patients with chronic disease. Eff Clin Pract 2001;4(6):256-262. [Medline: 11769298] 
42. Lorig KR, Ritter P, Stewart AL, Sobel DS, Brown BW, Bandura A, et al. Chronic disease self-management program: 2-year health status and health care utilization outcomes. Med Care 2001 Nov;39(11):1217-1223. [doi: 10.1097/00005650-200111000-00008] [Medline: $\underline{11606875]}$

43. Lorig KR, Ritter PL, González VM. Hispanic chronic disease self-management: a randomized community-based outcome trial. Nurs Res 2003;52(6):361-369. [doi: 10.1097/00006199-200311000-00003] [Medline: 14639082]

44. Self-Management Resource Center (SMRC). 2020. URL: https://www.selfmanagementresource.com/programs/ [accessed 2020-11-30]

45. Ory MG, Ahn S, Jiang L, Lorig K, Ritter P, Laurent DD, et al. National study of chronic disease self-management: six-month outcome findings. J Aging Health 2013 Oct 12;25(7):1258-1274. [doi: 10.1177/0898264313502531] [Medline: 24029414]

46. Choi N. Relationship between health service use and health information technology use among older adults: analysis of the US National Health Interview Survey. J Med Internet Res 2011 Apr 20;13(2):e33 [FREE Full text] [doi:

10.2196/jmir.1753] [Medline: 21752784]

47. Chung J, Gassert CA, Kim HS. Online health information use by participants in selected senior centres in Korea: current status of internet access and health information use by Korean older adults. Int J Older People Nurs 2011 Dec;6(4):261-271. [doi: 10.1111/j.1748-3743.2010.00238.x] [Medline: 21631875]

48. Reiners F, Sturm J, Bouw LJ, Wouters EJ. Sociodemographic factors influencing the use of eHealth in people with chronic diseases. Int J Environ Res Public Health 2019 Feb 21;16(4):645 [FREE Full text] [doi: 10.3390/ijerph16040645] [Medline: $\underline{30795623}$

49. Baumann E, Czerwinski F, Reifegerste D. Gender-specific determinants and patterns of online health information seeking: results from a representative German health survey. J Med Internet Res 2017 Apr 04;19(4):e92 [FREE Full text] [doi: 10.2196/jmir.6668] [Medline: 28377367]

50. Smith ML, Bergeron CD, Riggle SD, Meng L, Towne SD, Ahn S, et al. Self-care difficulties and reliance on support among vulnerable middle-aged and older adults with chronic conditions: a cross-sectional study. Maturitas 2017 Oct;104:1-10. [doi: 10.1016/j.maturitas.2017.06.030] [Medline: 28923169]

51. Smith ML, Bergeron CD, Adler CH, Patel A, Ahn S, Towne SD, et al. Factors associated with healthcare-related frustrations among adults with chronic conditions. Patient Educ Couns 2017 Jun;100(6):1185-1193. [doi: 10.1016/j.pec.2016.12.033] [Medline: 28117194]

52. Smith ML, Bergeron CD, Ahn S, Towne SD, Mingo CA, Robinson KT, et al. Engaging the underrepresented sex: male participation in Chronic Disease Self-Management Education (CDSME) programs. Am J Mens Health 2018 Jul 22;12(4):935-943 [FREE Full text] [doi: 10.1177/1557988317750943] [Medline: 29355070]

53. Silver MP. Patient perspectives on online health information and communication with doctors: a qualitative study of patients 50 years old and over. J Med Internet Res 2015 Jan 13;17(1):e19 [FREE Full text] [doi: 10.2196/jmir.3588] [Medline: 25586865]

54. Kivits J. Informed patients and the internet: a mediated context for consultations with health professionals. J Health Psychol 2006 Mar 01;11(2):269-282. [doi: 10.1177/1359105306061186] [Medline: 16464924]

55. Murray E, Lo B, Pollack L, Donelan K, Catania J, White M, et al. The impact of health information on the internet on the physician-patient relationship: patient perceptions. Arch Intern Med 2003 Jul 28;163(14):1727-1734. [doi: 10.1001/archinte.163.14.1727] [Medline: 12885689$]$

56. Ybarra M, Suman M. Reasons, assessments and actions taken: sex and age differences in uses of internet health information. Health Educ Res 2008 Jun 01;23(3):512-521. [doi: 10.1093/her/cyl062] [Medline: 16880222]

57. Broom A. Virtually he@lthy: the impact of internet use on disease experience and the doctor-patient relationship. Qual Health Res 2005 Mar 01;15(3):325-345. [doi: 10.1177/1049732304272916] [Medline: 15761103]

58. Chiu Y. Probing, impelling, but not offending doctors: the role of the internet as an information source for patients' interactions with doctors. Qual Health Res 2011 Dec 28;21(12):1658-1666. [doi: 10.1177/1049732311417455] [Medline: 21799204]

59. Camacho-Rivera M, Gonzalez CJ, Morency JA, Blake KD, Calixte R. Heterogeneity in trust of cancer information among hispanic adults in the United States: an analysis of the health information national trends survey. Cancer Epidemiol Biomarkers Prev 2020 Jul 01;29(7):1348-1356. [doi: 10.1158/1055-9965.epi-19-1375]

60. Gnjidic D, Hilmer SN, Blyth FM, Naganathan V, Waite L, Seibel MJ, et al. Polypharmacy cutoff and outcomes: five or more medicines were used to identify community-dwelling older men at risk of different adverse outcomes. J Clin Epidemiol 2012 Sep;65(9):989-995. [doi: 10.1016/j.jclinepi.2012.02.018] [Medline: 22742913]

61. Gnjidic D, Hilmer SN, Blyth FM, Naganathan V, Cumming RG, Handelsman DJ, et al. High-risk prescribing and incidence of frailty among older community-dwelling men. Clin Pharmacol Ther 2012 Mar 01;91(3):521-528. [doi: 10.1038/clpt.2011.258] [Medline: 22297385]

62. Sina M, Graffy J, Simmons D. Associations between barriers to self-care and diabetes complications among patients with type 2 diabetes. Diabetes Res Clin Pract 2018 Jul;141:126-131. [doi: 10.1016/j.diabres.2018.04.031] [Medline: 29689320]

63. Iverson S, Howard KB, Penney BK. Impact of internet use on health-related behaviors and the patient-physician relationship: a survey-based study and review. J Am Osteopath Assoc 2008 Dec;108(12):699-711. [Medline: 19075034] 
64. Bylund CL, Gueguen JA, D'Agostino TA, Li Y, Sonet E. Doctor-patient communication about cancer-related internet information. J Psychosoc Oncol 2010 Feb 22;28(2):127-142 [FREE Full text] [doi: 10.1080/07347330903570495] [Medline: 20391071]

65. Rahmqvist M, Bara A. Patients retrieving additional information via the internet: a trend analysis in a Swedish population, 2000-05. Scand J Public Health 2007 Sep 05;35(5):533-539. [doi: 10.1080/14034940701280750] [Medline: 17852982]

66. Stevenson FA, Kerr C, Murray E, Nazareth I. Information from the internet and the doctor-patient relationship: the patient perspective--a qualitative study. BMC Fam Pract 2007 Aug 16;8(1):47 [FREE Full text] [doi: 10.1186/1471-2296-8-47] [Medline: $\underline{17705836}$ ]

67. Campos-Castillo C. Revisiting the first-level digital divide in the United States: gender and race/ethnicity patterns, $2007-2012$. Soc Sci Comput Rev 2014 Aug 21;33(4):423-439. [doi: 10.1177/0894439314547617]

68. Klawitter E, Hargittai E. "“I Went Home to Google": How Users Assess the Credibility of Online Health Information". In: Hale TM, Chou WY, Cotten SR, Khilnani A, editors. eHealth: Current Evidence, Promises, Perils and Future Directions (Studies in Media and Communications, Vol. 15). Bingley, United Kingdom: Emerald Publishing Limited; 2018:11-41.

\section{Abbreviations \\ CDSMP: Chronic Disease Self-Management Program \\ OR: odds ratio}

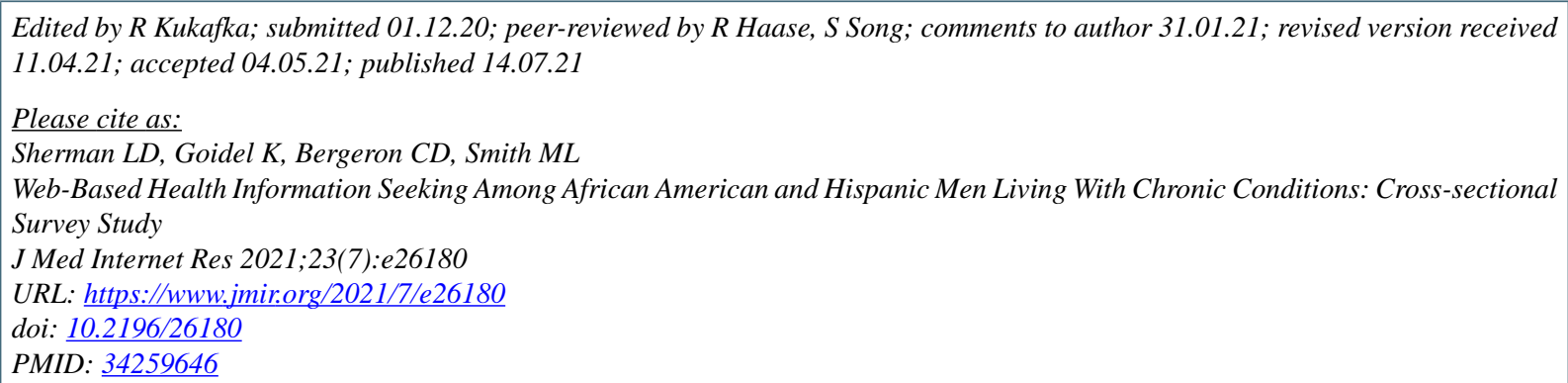

(CLedric D Sherman, Kirby Goidel, Caroline D Bergeron, Matthew Lee Smith. Originally published in the Journal of Medical Internet Research (https://www.jmir.org), 14.07.2021. This is an open-access article distributed under the terms of the Creative Commons Attribution License (https://creativecommons.org/licenses/by/4.0/), which permits unrestricted use, distribution, and reproduction in any medium, provided the original work, first published in the Journal of Medical Internet Research, is properly cited. The complete bibliographic information, a link to the original publication on https://www.jmir.org/, as well as this copyright and license information must be included. 